\title{
Human capabilities, mild autism, deafness and the morality of embryo selection
}

Pier Jaarsma and Stellan Welin

\section{Linköping University Post Print}

\section{Tweet}

N.B.: When citing this work, cite the original article.

The original publication is available at www.springerlink.com:

Pier Jaarsma and Stellan Welin, Human capabilities, mild autism, deafness and the morality of embryo selection, 2013, Medicine, Health care and Philosophy, (16), 4, 817-824.

http://dx.doi.org/10.1007/s11019-013-9464-6

Copyright: Springer Verlag (Germany)

http://www.springerlink.com/?MUD=MP

Postprint available at: Linköping University Electronic Press

http://urn.kb.se/resolve?urn=urn:nbn:se:liu:diva-89704 


\title{
Human capabilities, mild autism, deafness and the morality of embryo selection
}

Pier Jaarsma and Stellan Welin

\author{
Abstract A preimplantation genetic test to discriminate \\ between severe and mild autism spectrum disorder might \\ be developed in the foreseeable future. Recently, the philosophers \\ Julian Savulescu and Guy Kahane claimed that \\ there are strong reasons for prospective parents to make use \\ of such a test to prevent the birth of children who are \\ disposed to autism or Asperger's disorder. In this paper we \\ will criticize this claim. We will discuss the morality of \\ selection for mild autism in embryo selection in a hypothetical \\ in vitro fertilization (IVF) situation where preimplantation \\ genetic diagnosis is performed and compare this \\ with a similar selection for congenital deafness. To do this \\ we first discuss relevant human differences. We then \\ introduce the principle of human capabilities (PC) and \\ compare this principle with the principle of procreative \\ beneficence (PB) introduced by Savulescu and Kahane. We \\ apply the two principles to selection for mild autism and \\ selection for congenital deafness. We argue that PC allows \\ for the selection for mild autism but rules out selection for \\ congenital deafness. PB will not give clear answers; the \\ ruling of PB depends to a large extent on expected social, \\ cultural and political developments. We will argue that PC \\ is preferable to $\mathrm{PB}$. We will discuss arguments for the
}


value of mild autism for individuals who have this condition

and argue that they are able to lead a life with human

dignity provided autism-friendly social circumstances are

present. Neither PC nor PB yields strong reasons for prospective

parents to seek to prevent the birth of children who

are disposed to mild autism spectrum disorder.

Keywords Autism - Reproduction - Genetic selection -

Ethics - Human capabilities - Procreative beneficence -

Quality of life

\section{Introduction}

In this paper we will discuss the morality of selecting for mild autism in embryo selection in a hypothetical IVF situation where Preimplantation Genetic Diagnostics (PGD) ${ }^{1}$ is performed. We discuss this under the supposition that a genetic marker for mild autism like Asperger's Disorder ${ }^{2}$ can be found. This supposition is not so farfetched. The search for the genetic causes of autism is already in an advanced stage (Campbell 2010). A preimplantation genetic test to discriminate between severe and mild Autism Spectrum Disorder might be developed in the foreseeable future. The question is then: are prospective parents morally allowed to select a mildly autistic embryo instead of a "normal one" if they so wish?

We discuss these questions by introducing two principles. The principle of human capabilities (PC) states that it is wrong (if selection is possible) to willingly bring into

\footnotetext{
${ }^{1}$ In a fertilized human egg (an early embryo) consisting of up to 8 cells, one of the cells can be removed for genetic investigations. That cell is destroyed in the process but the rest of the embryo develops in a normal way.

${ }^{2}$ The Diagnostic and Statistical Manual of Mental Disorders, fourth edition, the DSM-IV-TR, states that the primary diagnostic abnormalities in autistic disorder are: qualitative impairment in social interaction, qualitative impairments in communication, and restricted repetitive and stereotyped patterns of behavior, interests, and activities. Autism Spectrum Disorder has Asperger's disorder at the mild end, and severe autistic disorder at the other end. Asperger's Disorder differs from 'classic' Autism in that those diagnosed with Asperger's do not show evidence of intellectual deficiency or language delay.
} 
the world a child lacking a central human capability, like hearing, if a hearing child could have been born. The principle of procreative beneficence (PB), formulated by Savulescu and Kahane, states roughly that parents should choose (if there is a choice) to have children with the best possible life expectations. Savulescu and Kahane use PB among other things to argue prospective parents should prevent the birth of a child disposed to autism or Asperger's Disorder, because of the severe impairment in social skills. We disagree with Savulescu and Kahane in the case of mild autism.

We will first give our view of mild autism as a natural and potentially healthy human variation, and then introduce the two principles. Then follows an argument for the moral permissibility of choosing an autistic embryo (if parents so wish) based on the principle of human capabilities and our view of human differences. After that we will give arguments why PC is better and more intuitive than PB. At the end we will argue that even if one accepts PB in Savulescu and Kahane's version, this will not lead to the conclusion they believe in, with regard to mild autism.

\section{Natural and healthy human differences}

Persons who are on the milder side of the autistic spectrum are different from 'ordinary' neurotypicals. ${ }^{3}$ There is no way a person with congenital autism can be changed into a neurotypical or vice versa. ${ }^{4}$ There are differences in their brains. ${ }^{5}$ In the following discussion we assume that there are genetic markers for the development of an autistic brain, markers that can be found in embryos in an IVF situation and detected via Preimplantation Genetic Diagnosis. Whether this genetic disposition to develop an autistic brain is inherited or just a random phenomenon does not matter. What matters is when the difference is developed. If it is a random process late in fetal development, PGD cannot be used for selection. It is not yet possible to choose for or against a mildly autistic embryo in a PGD situation. We discuss the situation when this will become possible.

\footnotetext{
${ }^{3}$ The term 'neurotypical' is used by people with autism spectrum conditions for people without such conditions.

${ }^{4}$ A neurotypical person appears to be able to change into a person with autistic-like behavior. When young children are reared in depriving circumstances, they may develop Post-Institutional Autistic Syndrome, also called 'quasi-autism' (Rutter et al 2010).

${ }^{5}$ Contemporary research suggests the presence of minicolumnopathy (minicolumnar abnormalities in the brain) in autism (Williams and Casanova 2010; Casanova et al 2010).
} 
A natural and healthy human difference is the difference between being homosexual or heterosexual. A rather common idea is that there is something in the brain that makes the difference. Homosexuality was for a long time considered a sin, then a pathological state to be treated (if possible) and now is seen as a natural and healthy variation. Homosexuality moved out of the psychiatric diagnostic manuals relatively late. In many parts of the world it is still regarded as a serious sin in a religious sense and carries heavy penalties if discovered.

Another natural and healthy human difference is the difference between being male or female. There are definite genetic markers for being male or female. It is a random process at fertilization, but it is possible to select for male or female human embryos in an IVF situation. Even if men and women to a large extent are similar, there are certain differences. Some of the differences are due to different reproductive organs and secondary sex characteristics but there may also be differences in the brain. There are people who have developed (say) a male body but feel that they really are female. One possible explanation is that in this male body there exists a 'female' brain. ${ }^{67}$ Another explanation is that there is some psychological condition causing this feeling of being in the wrong body. ${ }^{8}$ If there is a 'female' brain (or a female gender identity) in a male body, the preferred treatment (in severe cases) is a sex change operation.

Could autism, either the severe or the mild form of it, also be a natural and healthy human difference? Ian Hacking, a philosopher with an interest in autism, does not seem to think so. He judges autism to be a devastating disorder to the family (Hacking 2009). He mentions some of the difficulties of living with core autism: no response; no affect; obsessed with things and order; no play with other children; echolalia; violent tantrums. Hacking compares autism with Down's syndrome and articulates a horrifying metaphor:

\footnotetext{
${ }^{6}$ According to Kruijver et al. there may be a neurobiological basis of gender identity disorder (Kruijver et al. 2000). Recent Magnetic Resonance Imaging research sheds a different light on this matter. '[r]egional gray matter variation in MTF (male to female) transsexuals is more similar to the pattern found in men than in women (Luders et al. 2009).' However, Luders et al. support the assumption that brain anatomy plays a role in gender identity.

${ }^{7}$ According to Garcia-Falgueras and Swaab (2010) our gender identity (the conviction of belonging to the male or female gender) is intrauterinely programmed or organized into our brain structures.

${ }^{8}$ This 'psychological' explanation is highly debatable. 'Some studies, [...], suggest that instead of being preconditions for the development of GID (Gender Identity Disorder), psychiatric problems may be the consequences of persistent psychological difficulties due to the incongruence of biological sex and gender identity on the one hand and the social rejection on the other (Lajos et al. 2011).'
} 
Serious Down's syndrome is pretty bad too, but despite all the difficulties, physical and mental, there is a loving little child there. That is what is so dreadful about core autism: your child is an alien.

Hacking concludes by saying that bringing up a child with core autism demands a lot of courage and persistence. The prospect of bringing up a child with severe or 'core' autism can indeed be a good reason to opt for a non-autistic embryo through PGD. On the other hand, the prospect of bringing up a child with 'mild' autism, like Asperger's Disorder, might not be such a good reason. Hacking is partially right in claiming that autism is a devastating disorder. However, our claim is that autism, especially mild autism, is not necessarily devastating, either to the family or to the person with autism.

The relation between men and women is in some sense analogous to the relation between autistic people (on the mild side of the autistic spectrum) and 'ordinary' neurotypicals. It might be just as hard for a person with autism to imagine him- or herself to be neurotypical or vice versa as it is for a man to imagine himself to be a woman or, again, vice versa. According to Simon Baron-Cohen, the autistic brain is an extreme male brain (Baron-Cohen 2002b, 2011). ${ }^{9}$ Persons with autism are 'hypoempathizers', but at the same time 'hypersystemizers'. Hypothetically, there might also be hyperempathizers, who are, at the same time, hyposystemizers. One might call this 'The Extreme Female Brain'. ${ }^{10}$ There is no known way to change the female brain into a male one. Likewise there is no known way to change an autistic brain into a neurotypical one. The mild variation of the extreme male brain should be regarded as a difference rather than a defect (Jaarsma and Welin 2012).

In contrast, severe deafness cannot be seen as just a difference. Severe deafness is usually judged bad: a central human capability is severely lacking. A member of the Deaf Community might object that deafness is valuable because without it one cannot experience the inability to hear (which is different than simply not hearing because of earplugs, etc.). People who are not deaf can never really "get it" and so can never be fully a part of the Deaf Community. But this argument, though seemingly plausible, is mistaken. People who never

\footnotetext{
${ }^{9}$ Although this is a very influential theory, we do not wish to suggest that the extreme male brain theory of autism has reached scientific consensus.

10 "All we know about the extreme female brain is that, [...] it is predicted to arise. [...] Their empathizing would be significantly better than other people in the general population, but their systemizing would be impaired. These would be people who have difficulty understanding maths or physics or machines or chemistry as systems, but who are extremely good at tuning in to others' feelings and thoughts (Baron-Cohen 2002b, p. 253)."
} 
used drugs (the illegal ones) can also never really "get it" what it's like to get high on those particular drugs. However, that particular experience is not necessary to know that drugs are a bad thing, on average, both for the health of the user and for society. Likewise, the experience of deafness is not necessary to know that deafness is a bad thing, on average.

Moreover, the existence per se of the Deaf Community is not uncontroversial. As long as the Deaf are discriminated against, the Deaf Community has utility to counteract this injustice. But if it is possible to integrate the Deaf in main stream society, this would arguably be preferable to the exclusion inherent in defining oneself or somebody else as a member of the Deaf Community. The unfortunately now extinct 'Martha's Vineyard Sign Language' proves this point. It allowed deaf residents of the island of Martha's Vineyard ${ }^{11}$ to smoothly integrate into society. On Martha Vineyard there was no need for a Deaf Community. In an ideal world there shouldn't be a need for a Deaf Community either.

\section{Two principles for procreative choices}

Next we turn to a PGD situation for a couple where there is a choice between embryos to be made. We have two kinds of choice situations in mind. One is between an autistic embryo and a non-autistic (Neurotypical) embryo and the other is between a hearing and a deaf embryo. (That the embryo is called autistic or deaf simply means that the resulting child will have such a characteristic.) What does the principle of human capabilities say about these choices and what does the principle of procreative beneficence say according to Savulescu and Kahane. (We argue later that they are wrong about the case of mild autism even if one accepts PB.)

\section{The principle of human capabilities $(P C)$}

In 1985 a study reported that genetically blind, egg producing hens had a better life than their sighted comrades (Ali and Cheng 1985). Later doubts have been cast on this particular claim, but the mere suggestion that lack of a central capability is valuable and that it enhances the quality of life, is troubling (Collins et al. 2011). Although probably there will be cultural

\footnotetext{
11، Through a mutation, a recessive gene brought out by inbreeding, a form of hereditary deafness existed for 250 years on Martha's Vineyard, Massachusetts, following the arrival of the first deaf settlers in the 1690's. By the mid nineteenth century [...] the incidence of deafness had risen to one in four. In response to this, the entire community learned Sign, and there was free and complete intercourse between the hearing and the deaf. Indeed the deaf were scarcely seen as 'deaf', and certainly not seen as being at all 'handicapped' (Sacks, 1989, p. 33)."
} 
differences, most people would react with repulsion to the idea that we should select for blind hens for egg production. Obviously, hens are not humans, but the emotion underlying this 'yuck' factor is not necessarily irrational. Emotions have cognitive or rational significance and they can have 'evaluative propositional content' (Greenspan 2004, p. 125). They can be seen as judgments of value and importance (Nussbaum 2004, p. 183). ${ }^{12}$ We claim that this particular emotion of repulsion, in this case, relates to two intuitions, one descriptive (a statement of fact) and the other normative (a judgment of value):

1. There are natural endowments or capabilities.

2. It is morally wrong to select for traits where central capabilities are missing.

Deafness is a severe lack of a central human capability. A deaf person is not just different to a hearing person in the sense that mildly autistic persons are different to neurotypicals, homosexuals different to heterosexual persons or men different to women. A non-hearing person is lacking something, namely the capability for hearing. The repulsion we feel to the idea that we should select for blind hens for egg production is similar to the repulsion we would feel if we should select for deafness in IVF situations, if a hearing embryo could be chosen. The basis for this repulsion is an intuition of natural human endowments or capabilities. It would be immoral to select for traits where central human capabilities are missing. The principle of human capabilities articulates these intuitions.

Principle of human capabilities $(P C)$ : It is morally wrong to knowingly and willingly bring into the world a human being lacking severely a basic central human functional capability if a human being who has a sufficient level of each and every basic central human functional capability could be brought into the world.

We substantiate our principle with Martha Nussbaum's list of central human functional capabilities, the philosophical pendant of Amartya Sen's capabilities approach. In order to lead a life with human dignity, a person needs 'human goods (Glover, 2006, p. 89)'. Martha Nussbaum has formulated a list of these human goods, which she calls central human

\footnotetext{
${ }^{12}$ The blind hen analogy may seem a bit farfetched. However, we believe it serves pretty well to illustrate the intuition that is at work in the (for humans) more important matter of choosing embryos without one or more central human functional capabilities. The function of the analogy is not to convince, merely to compare it with the intuition ('emotion' or 'upheaval of thought') at work in the case of choosing embryos without one or more central human functional capabilities.
} 
functional capabilities: life; bodily health; bodily integrity; senses, imagination, and thought; emotions; practical reason; affiliation; other species; play; control over one's environment (Nussbaum 2006, p. 76). The ten capabilities are central requirements of a human life with dignity. ${ }^{13}$ The qualifier 'basic' in our definition of PC refers to "the innate faculties of the person that make later development and training possible (Nussbaum 2011, p. 24)." 14

With respect to the capability of 'senses': some believe that selecting for congenital deafness is permissible. An argument for this position is that "deafness does not reduce well-being because signing is a unique form of communication that offers access to a unique culture that can only be fully experienced by the deaf (Savulescu and Kahane 2009, p. 288)". We will argue that PC allows for the selection for mild autism if the prospective parents prefer a mildly autistic child, but rules out selection for congenital deafness. ${ }^{15}$ (Selecting for such traits as deafness is ruled out by PC but can be allowed for by PB. We will discuss PB and deafness later on.)

This principle can be employed in all situations involving possible choices that may affect the future child. In an IVF situation with PGD, it is wrong to select for an embryo that would give rise to a deaf child or to a severely hearing impaired child. If one of the partners has a recessive gene for deafness, then we would recommend IVF and PGD and selection for an embryo with just one such gene for congenital deafness. ${ }^{16}$

In particular PC makes no recommendations between choosing a male or female embryo, a gay or heterosexual embryo (if that was possible). PC does not recommend nor recommend against choosing a mildly autistic embryo. Neither of the above categories is lacking severely a capability. They are just different and the capabilities are realized in different ways (Jaarsma and Welin 2012). In contrast, being deaf is lacking severely a central human capability, namely hearing.

The principle PC is not perhaps absolutely clear cut. There are vague cases but we believe that it must be formulated in terms of "sufficient" and "lacking severely". It seems that the only way to avoid this fuzziness would be to state that all natural endowments should

\footnotetext{
13 "All these capabilities are implicit in the idea of a life worthy of human dignity (Nussbaum 2006, p. 70)." "Any child born into a species has the dignity relevant to that species, whether or not it seems to have the "basic capabilities" relevant to that species. For that reason, it should also have all the capabilities relevant to the species [...] (Nussbaum 2006, p. 347)."

${ }^{14}$ Emphasis added.

${ }^{15}$ Selecting for such traits as deafness is ruled out by PC but can be allowed for by PB. We will discuss PB and deafness later on.

${ }^{16}$ E.g. autosomal recessive deafness 1A (DFNB1A) (Barashkov et al. 2011).
} 
be present in the full sense. This would rather be a principle of human perfection. It would be quite useless; there will seldom be a perfect embryo to choose in an IVF situation, only embryos sufficiently perfect.

In severe deafness a central human functional capability is severely missing, namely one of the senses. Deafness cannot be seen as just a 'difference', like for instance homosexuality. Neither is deafness intrinsically bad. When something is intrinsically bad, it is bad in all possible worlds (Savulescu and Kahane 2009, p. 286). Deafness may be an instrumentally good or neutral thing, depending on the person and the circumstances. For instance when one lives in the neighborhood of a busy highway or airport, it may be judged instrumentally good or neutral. However, on average, deafness is instrumentally bad, as it is the main reason for communication difficulties between hearing and hearing-impaired persons.

Admittedly, there are degrees of hearing-impairment going from a mild impairment to total deafness. If it is only a minor hearing-impairment, this is not a case where "central capabilities are missing". A major hearing impairment involves missing a central capability.

What if a cochlear transplant is performed and the formerly severely impaired person can be made hearing? In our intuitions such person still misses a "natural" human capability and furthermore, if the plan is to first select for deafness and then do a cochlear transplant, then this particular choice is rather pointless. We think that to select for deafness and not doing a cochlear transplant to make the child hearing is wrong.

In severe autism the central human capabilities of imagination, emotions and affiliation are severely missing. Intuitively, it would be immoral to select for traits where central human capabilities are severely missing. In mild autism central human functional capabilities are mildly missing. However, mild autism can be experienced as severe by an affected individual, due to the interplay of socially constructed barriers ${ }^{17}$ and the specific impairments of the person with mild autism.

The principle of procreative beneficence $(P B)$

\footnotetext{
${ }^{17}$ See e.g. Clarke, 2008.
} 
Recently, the philosophers Julian Savulescu and Guy Kahane (2009, p. 281) claimed that there are strong reasons for prospective parents to seek to prevent the birth of a child disposed to autism or Asperger's Disorder, because of the severe impairment in social skills. The structure of their argument is the following:

Premise 1: It is a moral obligation to create children with the best chance of the best life.

Premise 2: Embryos with severe impairments can never have the best chance of the best life.

Premise 3: Embryos with autism, even mild autism (like Asperger's Disorder), have severe impairments.

Conclusion: It is a moral obligation not to choose embryos with autism, not even mild autism.

Savulescu and Kahane (2009, p. 274) formulate the principle of procreative beneficence (PB) as follows: "If couples (or single reproducers) have decided to have a child, and selection is possible, then they have a significant moral reason to select the child, of the possible children they could have, whose life can be expected, in light of the relevant available information, to go best or at least not worse than any of the others."

The aim of PB is to ensure the best chance of the best life for the becoming child. As the parents do not know the future life for their child, all choices must be made on estimates and probability guesses about the future. However there are some problems in the application of PB as discussed below.

Problems with the principle of procreative beneficence compared to the principle of human capabilities

The future of society is heavily dependent on cultural and political development and trends. PB would have ruled against selection for a female embryo in the old days when men generally had much better lives. PB would also have ruled against homosexuals in the old days. No such recommendation should be made today in the Western world. In other parts of the world, e.g. in countries where women and gays are still discriminated, PB would rule 
against female and gay embryos. ${ }^{18}$ Different choices must be based on a changed political situation in such a state or on a prediction of a successful emigration to a more tolerant country.

PC is not affected by political or social changes. It will recommend the same choice whatsoever. As we do not believe that gay people are lacking any human capability, PC does not recommend selecting against a gay embryo. If the political situation of homophobia and discrimination of women in a country could be predicted with high probability to prevail, then PB rules against selecting gay as well as female embryos. PC does not make such recommendations.

Savulescu and Kahane's claim that reproducers have strong reasons to seek to prevent the birth of a child with Asperger's syndrome can only make sense in an autismphobic society. If we should allow such reasons to be valid, one should seek to prevent the birth of homosexuals in a homophobic society, the birth of colored people in a racist society and even the birth of women in a sexist society. These are all counterintuitive outcomes of PB. Unlike PC, PB cements social inequalities. PC leaves it entirely up to the individual reproducer whether or not he or she wants to give in to societal inequalities or not. PC does not recommend selecting against a gay embryo, a female embryo or, for that matter, an embryo with the genetic makeup for mild autism, although it does recommend selecting against an embryo with the genetic makeup for severe autism.

Morality is about individual choices. It is the individual who is responsible for procreative choices even if such choices often are made together with a partner. Also, each possible situation of choice can be important, not just IVF choice situations. Therefore a wider and more natural application can be formulated as the

Principle of wider procreative beneficence (WPB): each individual considering procreation should aim, in each possible situation, where a choice can be made that may affect the future embryo and child, for the best chance of the best possible life for the child-to-be.

There are many choice situations when WPB can be applied. The individual must start before he or she has a partner. As a start they should be looking for the 'best' partner or the best donor of sperm cells and eggs. If it is a male, who wants to procreate, this may involve looking for a surrogate mother or for a partner willing to implant the best egg and carry the

\footnotetext{
${ }^{18}$ Assuming there is a genetic marker for homosexuality.
} 
fetus to birth. If it is a woman, it can be enough to find a donor with good sperm cells. The WPB rules against single parenting in all societies where they are discriminated against. Furthermore, in most developed countries WPB strongly recommends teaming up with a rich partner. Then the child's life will probably be better.

If there already is a couple, then according to WPB, they should look for the best available eggs and sperm cells to use. (Not just their own). After the birth of the child the couple should seriously consider if another family could give the child a better chance and hence put that child up for adoption.

We believe that WPB is unreasonable and that PB is too restrictive. When PC is applied to other possible choices it will not give counterintuitive outcomes. It does give some recommendations. If you want to have a child with a congenitally deaf person, you should make sure to have PGD and select for a hearing embryo. If you are congenitally deaf and are interested in starting a family with a congenitally deaf person, you should (before you conceive) find out if you and your partner have the dominant or recessive genes. If both have the dominant version, you should not try conceiving a child together by intercourse. You could go for PGD and pick a 'hearing' embryo or go for donated eggs or sperm cells. What if your situation is such that you cannot afford PGD? This is an important question not discussed here.

It is not necessary for prospective parents to go for the best chance of the best life. It is sufficient for an embryo to have enough of each and every capability to be eligible according to PC. What is morally important with respect to capabilities is for everyone to have enough. In this context, Savulescu and Kahane deem 'sufficiency' (or 'the satisficing principle' as they call it (Savulescu and Kahane 2009, p. 281)) implausible. We disagree with their view. Instead we base our view on Martha Nussbaum's notion of a life worthy of human dignity. To be able to lead a life worthy of human dignity it is sufficient to have a threshold level of the ten central human functional capabilities (Nussbaum 2011, p. 32-33). Opting for the best chance of the best possible life may be a good strategy for a farmer in the pursuit of the best life stock, but when human beings are involved, dignity begins to matter. Therefore, Savulescu and Kahane's project of making it obligatory to choose only the embryo with the best chance of the best possible life is at odds with human dignity.

For these reasons premise 1 of Savulescu and Kahane's argument is unconvincing. However, it may be the case that it is indeed our rejection of PB that is unconvincing. In that case the argument of Savulescu and Kahane, as specified above can still 
be falsified through the rejection of the third premise: "Embryos with autism, even mild autism (like Asperger's Disorder), have severe impairments."

\section{Reasoning from the principle of procreative beneficence: mild autism can be valuable}

In this section, we will argue that mild autism can be valuable, i.e. it is possible that the advantages of mild autism (Asperger's disorder included) outweigh the disadvantages. Someone might object that mild autism cannot be valuable because persons with mild autism are lacking in central human functional capabilities, namely the capabilities of imagination, emotions and affiliation. However, according to Simon Baron-Cohen, one of the leading autism experts, these deficits can be explained by the extreme male brain theory of autism. Autism, according to this theory, is a matter of hyper-systemizing and hypo-empathizing. In contradistinction to psychopaths, who also have an empathy deficit but one that can only be valued negatively, the empathy deficit of persons with mild autism can still be valued in a positive way because of the presence of a hypersystemizing ability in these persons (BaronCohen 2011).

It is obvious that mild autism, just as deafness, can be instrumentally bad, as it is the main reason for communication difficulties between persons with mild autism and neurotypicals. However, in deafness there are no compensating capabilities present. This particular point makes deafness just a matter of impairment. Mild autism, on the other hand, is not just a matter of impairment, because of compensating capabilities. To do justice to these compensating capabilities we should not refer to mild autism as a disability but rather as a 'difference'. It can be bad, neutral or good, depending on the external and internal

circumstances of the person with mild autism. External circumstances can be described in social, cultural or economic terms, while internal circumstances can be described in terms of quantity and quality of compensating capabilities. Mild autism can be valuable, for the person him- or herself, because of these compensating capabilities.

What is the nature of these compensating capabilities? Persons with mild autism have different ways of attending to details, searching for and finding patterns in such details, and more generally, they "not only have intact systemizing but also accelerated or superior development in this domain.' Autism is associated with scientific, especially mathematical skills (Baron-Cohen et al. 2001; Baron-Cohen et al. 2007). Creativity also has been linked to Autism and Asperger's syndrome; in which traits of perseverance, drive for perfection, 
disregard of social conventions and others' opinions allow creativity (Fitzgerald 2004; Fung 2009). The aspect of autism that predisposes to talent is a detail-focused cognitive style (Happé and Vital 2010). This excellent attention to detail, itself a consequence of sensory hypersensitivity, is claimed to be a universal feature of the autistic brain (Baron-Cohen et al. 2010).

Temple Grandin, autism advocate and animal welfare scientist, argues against prevention of autism by emphasizing the value of autism for society (Grandin 2006). However, whether or not autism can be valuable for society is irrelevant for the question whether we should allow selecting embryos for mild autism. What matters is the individualistic capability to lead a good life. A person's autism should be mainly valuable for him- or herself. However, this individualistic capability is dependent on limitations determined by the social, cultural and economic context. One study of blogs written by persons with Asperger's Disorder emphasizes that "they are happy with who they are and that any suffering they may have undergone has been the result of society and not inherent in their condition (Clarke, 2008, p 85)." “Autobiographies of people with AS [Asperger's Syndrome] suggest that the most harmful aspect of AS ([...] from the perspective of those with AS) is the inability of those without AS to comprehend the perspective of the AS mind and the way in which AS people experience their sensory world, i.e. their difference becomes a disability only because of how others respond to their differences (Allred, 2009, p. 351).” Responses of others to the differences of persons with mild autism lead to the formation of 'socially constructed barriers'.

Socially constructed barriers are an important reason for the difficulties persons with mild autism experience. To give an example of a socially constructed barrier: the size of school classes (a socially constructed fact) is relevant for the chance of thriving of children with mild autism. It has been acknowledged that smaller classes lead to higher academic learning progresses, better knowledge of students, and better classroom processes (Brühwiler and Blatchford 2011). When this is already beneficial for neurotypical children, this will apply, presumably, a fortiori for children with mild autism. Therefore it seems plausible that children with mild autism will be more likely to thrive in small school classes.

Philosopher Deborah Barnbaum (2008), who wrote extensively about the ethics of autism, holds the same position as Savulescu and Kahane in claiming that parents are obligated to do what they can to prevent the birth of an autistic child. Deborah Barnbaum bases her conclusion on a child's right to an open future. Similar claims had been made by philosophers Dena Davis (Davis, 1997) and Jürgen Habermas (Habermas, 2003). Savulescu 
claims that "Respecting a child's right to an open future means that we shouldn't determine the genetic endowment of future children out of respect for their future autonomy. [I]f respect for future autonomy is understood to benefit a person because it contributes to her well-being, then it is entirely compatible with PB (Savulescu and Kahane 2009, p. 282)." This is a strange interpretation. If there really was a uniquely best way of life for a particular child, that child would have the best chances of a good life if the possibilities were restricted to just this uniquely best possible life. An open future might include many bad possible lives.

Barnbaum differs from us in the respect that she does not distinguish between severe and mild autism. We discuss here the case when genetic markers distinguishing between severe and mild disorders on the Autism Spectrum are located. We therefore arrive at different conclusions for severe and mild autism. However, we agree with Barnbaum in the case of severe autism.

To conclude, mildly autistic persons can have a good quality of life, provided that they have a social environment that recognizes and acts sufficiently on their specific social and emotional needs. Socially constructed barriers for persons with mild autism need to be removed. An autism-friendly set of social circumstances is necessary to give persons with mild autism the capability to lead a life with human dignity. Persons with mild autism are not intrinsically severely impaired and so Premise 3 of Savulescu and Kahane's argument must be rejected.

\section{Conclusion}

It is morally permissible for parents to choose a mildly autistic embryo in a PGD situation if they so wish. This follows from the principle of human capabilities as well as from the principle of procreative beneficence - if one gets the fact about mild autism right.

Acknowledgements We are grateful to the anonymous reviewers for valuable comments.

\section{References}

Ali, A., and K.M. Cheng. 1985. Early egg production in genetically blind (rc/rc) chickens in comparison with sighted (Rc/rc) controls. Poultry Sci 64: 789-794.

Allred, S. 2009. Reframing Asperger syndrome: Lessons from other challenges to the diagnostic and statistical manual and ICIDH approaches. Disability and Society, 24(3), 343-355. 
Barashkov, N.A., L.U. Dzhemileva, S.A. Fedorova, F.M. Teryutin, O.L. Posukh, E.E. Fedotova, S.L. Lobov, and E.K. Khusnutdinova. 2011. Autosomal recessive deafness 1A (DFNB1A) in Yakut population isolate in Eastern Siberia: extensive accumulation of the splice site mutation IVS1+1G>A in GJB2 gene as a result of founder effect. J Hum Genet 56(9): 631-9.

Barnbaum, Deborah R. 2008. Ethics of Autism: Among Them, but Not of Them. Bloomington, IN, USA: Indiana University Press.

Baron-Cohen, S., S. Wheelwright, R. Skinner, J. Martin, and E. Clubley. 2001. The Autism-Spectrum Quotient (AQ): Evidence from Asperger Syndrome/High-Functioning Autism, Males and Females, Scientists and Mathematicians. Journal of Autism and Developmental Disorders 31(1).

Baron-Cohen S. 2002a. Is Asperger Syndrome Necessarily Viewed as a Disability? Focus on autism and other developmental disabilities 2002; 17(3): 186-191

Baron-Cohen S. 2002b. The extreme male brain theory of autism. Trends in Cognitive Sciences 6(6): 253.

Baron-Cohen, S., S. Wheelwright, A. Burtenshaw, and E. Hobson. 2007. Mathematical Talent is Linked to Autism. Human Nature 18: 125-131.

Baron-Cohen S., E. Ashwin, C. Ashwin, T. Tavassoli and B. Chakrabarti. 2010. Talent in autism: hypersystemizing, hyper-attention to detail and sensory hyper-sensitivity. In: Francesca Happé and Uta Frith (eds). 2010. Autism and Talent. Oxford: Oxford University press.

Baron-Cohen S., M.V. Lombardo, B. Auyeung, E. Ashwin, B. Chakrabarti, and R. Knickmeyer. 2011. Why are autism spectrum conditions more prevalent in males? PLoS Biol 9(6):e1001081. Epub 2011 Jun 14.

Baron-Cohen S. 2011. The science of evil. New York: Basic books.

Brühwiler C. and P. Blatchford. 2011. Effects of class size and adaptive teaching competency on classroom processes and academic outcome. Learning \& Instruction 21(1): 95-108.

Campbell, D. B. 2010. Advances and Challenges in the Genetics of Autism. Focus 8(3): 339-349.

Casanova M.F., A. El-Baz , E.Vanbogaert , P. Narahari , and A. Switala. 2010. A topographic study of minicolumnar core width by lamina comparison between autistic subjects and controls: possible minicolumnar disruption due to an anatomical element in-common to multiple laminae. Brain Pathol 20(2): 451-8.

Clarke, J. and G. van Amerom 2008. 'Asperger's Syndrome', Social Work in Health Care, 46: 3, 85-106.

Collins, S., B. Forkman, H.H. Kristensen, P. Sandöe, and P. M. Hocking. 2011. Investigating the importance of vision in poultry: Comparing the behavior of blind and sighted chickens. Applied Animal Behaviour Science 133: 60-69.

Davis, D.S. 1997. Genetic Dilemmas and the Child's Right to an Open Future. Hastings Center Report 27 (2):715.

Fitzgerald, M. 2004. Autism and creativity: is there a link between Autism in men and exceptional ability? New York: Brunner-Routledge.

Fung, C.H.M. 2009. Asperger's and musical creativity: The case of Erik Satie. Personality and Individual Differences 46: 775-783.

Garcia-Falgueras, A., and D.F. Swaab, 2010. Sexual hormones and the brain: an essential alliance for sexual identity and sexual orientation. Endocr Dev 17: 22-35.

Glover, J. 2006. Choosing children; genes, disability, and design. Clarendon press: Oxford.

Grandin, T. 2006. Thinking in Pictures: My Life with Autism, Expanded Edition. Westminster, Maryland: Knopf Publishing Group.

Greenspan, P. (2004) Emotions, rationality and mind/body. In: Thinking about feeling; contemporary philosophers on emotions, Ed. by R.C. Solomon. Oxford/Oxford University Press. 
Habermas, J. 2003. The future of human nature. Cambridge: Polity Press.

Hacking I. 2009. Autistic Autobiography. Phil Trans R Soc B 364, 1467-1473.

Happé F. and P.Vital. 2010. What aspects of autism predispose to talent? In: Francesca Happé and Uta Frith (eds). Autism and Talent. Oxford: Oxford University Press.

Jaarsma P., and S. Welin. 2012. Autism as a Natural Human Variation: Reflections on the Claims of the Neurodiversity Movement. Health Care Anal 20: 20-30.

Kruijver F.P., J.N. Zhou, C.W. Pool, M.A. Hofman, L.J. Gooren, and D.F. Swaab. 2000. Male-to-female transsexuals have female neuron numbers in a limbic nucleus. J Clin Endocrinol Metab 2000; 85(5): 2034-41.

Lajos S., U. Zsolt, D. Fogd, and P. Czobor. 2011. Dysfunctional core beliefs, perceived parenting behavior and psychopathology in gender identity disorder: A comparison of male-to-female, female-to-male transsexual and nontranssexual control subjects. J Behav Ther \& Exp Psychiat 42: 38-45.

Luders E., F.J. Sánchez, C. Gaser, A.W. Toga, K.L. Narr, L.S. Hamilton, and E. Vilain. 2009. Regional gray matter variation in male-to-female transsexualism.. Neuroimage 15; 46(4): 904-7.

Nussbaum, M. 2004 Emotions as Judgments of value and importance. In: Thinking about feeling; contemporary philosophers on emotions, Ed. by R.C. Solomon. Oxford/Oxford University Press.

Nussbaum, M. 2006. Frontiers of justice; disability, nationality, species membership. Harvard: Harvard University press.

Nussbaum, M. 2011. Creating Capabilities : The Human Development Approach. Cumberland, RI, USA: Harvard University Press.

Rutter M., E.J. Sonuga-Barke and J. Castle. 2010. Investigating the impact of early institutional deprivation on development: background and research strategy of the English and Romanian Adoptees (ERA) study. Monogr Soc Res Child Dev 75(1): 1-20.

Sacks, O. 1989. Seeing voices. A journey into the world of the deaf. Berkeley and Los Angeles, CA, USA: University of California Press.

Savulescu, J., and G. Kahane. 2009. The moral obligation to create children with the best chance of the best life. Bioethics 23: 274-290.

Williams E.L., and M.F. Casanova. 2010. Autism or autisms? Finding the lowest common denominator. Bol Asoc Med P R 2010; 102(4): 17-24. 